\title{
Reflective Practitioners and Participant Observers in Autism Services
}

\author{
Managing Knowledge in UK Social Care
}

\author{
Joseph J. Long
}

\begin{abstract}
Aвstract: Situated practice research offers rich possibilities for recognising and developing practitioner knowledge in social care. In this article, I document the application of anthropological methods and thinking within a research programme in autism services. Drawing on Donald Schön's model of the reflective practitioner, I argue that participant observation, aimed at the holistic documentation of autism services, provides a means to systematic reflection, comparison and learning in order to inform practice. This approach stands to broaden the field of autism research from unidirectional models of knowledge 'translation' to include research and insights generated from services. I also advocate the relational nature of anthropology as a means to meaningfully engage autistic people with intellectual disabilities in research through collaboration with practitioner researchers.
\end{abstract}

KeYwords: action research, applied anthropology, autism spectrum condition, communities of practice, intellectual disability, knowledge management, practitioner research, situated research

This article reflects upon the application of anthropology in social care services for autistic people in the United Kingdom. Here, I describe the development of a research programme within Scottish Autism, a large service provider where I am a resident researcher. The article explores the possibilities of situated research as a means to foster critical reflection on autism support practice. In particular, I emphasise anthropology's primary heuristic of participant observation as a method through which social care practitioners can be empowered to undertake research. The relational nature of anthropological investigation is also proposed as a means to include supported autistic people meaningfully in research through collaboration with practitioner researchers. In addition to discussing the employment of anthropological methods in practice research, I demonstrate ways in which anthropological thinking is implicated in the wider project of recognising, sharing and ap- plying knowledge usually framed as 'knowledge management'. Drawing on Donald Schön's (1983) distinction between 'technical rationality' and 'reflection in action', I suggest that research embedded in services offers possibilities to broaden the field of autism research from unidirectional models of research 'translation' and generate important insights for day-to-day practice. In this way, academic research and practice-based research can be brought into constructive dialogue.

Anthropologists are increasingly finding roles outside the academy, and the work described here illustrates the possibilities afforded by one such role. British anthropology has long seen researchers working in health services, but less commonly in social care. Meanwhile there is a growing critical literature on autism in the social sciences, but little on the everyday dynamics of autism support services. In a field dominated by neuroscience and psychology, de-

Anthropology in Action, 27, no. 1 (Spring 2020): 35-45 (C) Berghahn Books and the Association for Anthropology in Action ISSN 0967-201X (Print) ISSN 1752-2285 (Online) doi:10.3167/aia.2020.270104

This article is distributed under the terms of the Creative Commons Attribution Noncommercial No Derivatives 4.0 International license (https://creativecommons.org/licenses/by-nc-nd/4.0/). For uses beyond those covered in the license contact Berghahn Books. 
mands from the autistic community to make autism research more inclusive and grounded in lived experience (Chown et al. 2017; Milton and Bracher 2013) have been coupled with a desire for greater focus on the services that autistic people receive (Pellicano et al. 2014). In this context, there is a clear role for holistic research on social care to understand how services can better support the wellbeing of autistic people.

\section{Autism and Social Care in the United Kingdom}

Autism is a neurodevelopmental condition clinically defined as 'autism spectrum disorder'. Diagnostic criteria characterise autism in terms of difficulties with communication and social interaction; restricted and repetitive behaviour and interests; and include sensory processing difficulties (American Psychiatric Association 2013). Around 1 per cent of the UK population is thought to be autistic (Brugha et al. 2011; MacKay et al. 2018). The spectrum metaphor reflects the wide range of developmental profiles that autistic people present - from individuals that live and work independently to those with additional intellectual disabilities and high support needs. It should be noted, however, that some find this twodimensional analogy limiting, considering the considerable heterogeneity in the way that autism manifests. The label of disorder also remains problematic for many, who prefer 'autism spectrum condition' or simply 'autism'. Autistic activists and researchers have argued for recognition of autism as a social identity (Sinclair 2012, 2013) and a way of being-in-the-world (Milton 2012) rather than as a purely clinical label. Critical studies of autism, many undertaken by autistic researchers, have championed a social model of disability to understand autism in its historical and cultural context (Woods et al. 2018). The autistic community has also advanced the concept of 'neurodiversity' as a term that recognises and celebrates human difference without employing the language of pathology to describe autistic differences from 'typical' developmental profiles (Singer 2017).

There is a growing literature on autism in anthropology and the social sciences that focusses on questions of social identity and the politics of biomedical science (see Belek 2019; Grinker 2008; Solomon 2010a; and Hollin 2014). There is also an emerging focus on autistic sociality in therapeutic processes (Malcolm et al. 2018; Solomon 2010b). There have been a small number of ethnographic studies of intellectual dis- ability services in recent decades (e.g. Angrosino 1998; Avery 2020; Gleason 1989), ${ }^{1}$ but little of this ethnography focuses on autism-specific provision. Moreover, this body of work has remained outside the purview of mainstream autism research. My focus here is on applied research in social care services for autism and the ways in which practical knowledge inheres and circulates in those contexts. I propose that attention to these topics can make a key contribution to the wider field of autism research.

Social care services in the United Kingdom include a broad range of support provision for people with long-term needs. These include older people, adults with disabilities and people with long-term mental health difficulties. Services are provided by a range of state, third sector and private organisations, and are commissioned and paid for by local government. Social care or 'supported-living' services for autistic people are not based on a clinical or health models but aim to provide community-based, personalised support in home environments. A recent report estimated around one-third of autistic adults in Scotland to have additional intellectual disabilities, with just over half of this group projected to live in social care settings. ${ }^{2}$ (MacKay et al. 2018).

Scottish Autism is a third-sector service provider. ${ }^{3}$ The organisation regularly supports 390 autistic individuals, mostly in adult social care services. Provision varies from outreach services for people who require only a few hours support per week, to roundthe-clock care for those with high support needs. Many individuals with intellectual disabilities supported by Scottish Autism do not communicate verbally and require continual support with daily living skills, personal care, accessing community amenities, and social opportunities. This support is provided by 820 social care practitioners.

\section{Translation and Reflection in the Generation of Autism Knowledge}

In his classic work, The Reflective Practitioner, Schön (1983) identified two models for the generation and application of professional knowledge. The first he termed 'technical rationality', in which scientific knowledge generated within the academy feeds into the education and collective knowledge base of graduate professions. The second Schön termed 'reflection in action', in which professionals gain insight and adjust their practice through critical reflection, taking a 'stance of inquiry' in viewing their own work. Though The Reflective Practitioner was written 
over 30 years ago, Schön's insights are highly pertinent to autism research and service provision today. His distinction between modes of knowledge generation maps neatly onto the way that clinical and social care services respectively utilise knowledge.

Technical rationality resembles closely the prevailing model of psychological research in which scientists seek the holy grail of 'translation' - scientific findings that will influence service provision (Woolf 2008). In this paradigm, the translation metaphor is unidirectional rather than dialogical. Autism research is dominated by work of this kind. A 2013 report found 56 per cent of autism research funding in the United Kingdom to be focused on the science of 'body, brain and cognition' and a further 18 per cent on causation (Pellicano et al. 2013). Applied autism research is largely characterised by clinical paradigms of 'treatment' and 'intervention': the same report found that this constituted 18 per cent of total funded research in the United Kingdom. To this end, scientific trials carefully measure the outcomes of behavioural, educational and clinical programmes to be adopted and replicated in practice. According to this model, strong fidelity to a programme is required, in order to replicate the trial (Aitken 2013; Mandell et al. 2013). ${ }^{4}$

In the day-to-day work of social care services, applying the vast corpus of published autism research literature is challenging: much of this research is generated in carefully controlled conditions that take little account of the exigencies of daily life. Moreover, such research is usually hidden behind paywalls, which make it inaccessible to social care practitioners. The possibilities for translating such research into individualised, community-based services are limited. Replicable 'interventions' might be appropriate for intensive support on acute mental health issues or for focussing on a particular need, but social care services are holistic and are not designed to focus on a single issue or variable. Moreover, the role of social care services is not to provide 'intervention' or 'treatment', but rather to support wellbeing and enable a meaningful life on supported autistic people's own terms. As such, Schön's 'reflection in action' model of professional learning is more likely to prevail: social care practitioners 'learn by doing' and make adjustments as they go along. As practitioners come to understand the needs of supported individuals, practice adjustments may, for example, include changing communication strategies; trying new activities; adapting an environment to account for sensory stressors; or providing social opportunities.

\section{Managing Knowledge in Autism Services}

Social care practitioners in autism and intellectual disability services in the United Kingdom are usually termed 'support workers' and are not professionals in the traditional sense: there is no higher-level educational qualification for social care, and the workforce is largely employed with unskilled status and pay. Social care practitioners undertake training while in post to achieve National Vocational Qualifications or Scottish Vocational Qualifications in order to certify an understanding of generic social care policy, standards, and practices. Training specific to autism is the responsibility of service-providing organisations. In practice, social care practitioners have a wide range of education and skills - some have higher or postgraduate qualifications, while others will have none. Some practitioners are autistic themselves, while many gain considerable insight and experience in supporting autistic people through their work, sometimes supporting individuals over many years.

In this respect, much of the knowledge and skill of practitioners supporting autistic people are acquired through informal learning, peer-to-peer interactions, and ongoing relationships with the autistic people that they support. Many learnt skills such as personalised communication or stress reduction are constituted in the day-to-day support of individuals and may be tacitly held by practitioners rather than consciously deployed. ${ }^{5}$

At Scottish Autism, the geographical distribution of supported tenancies and day placements historically led to an element of isolation within services. Skills, knowledge, and practical support strategies were developed in particular locations but remained located there (what is often described as 'the silo effect') rather than being captured or shared in ways that could inform services elsewhere (Guldberg et al. 2013). These two phenomena - the tacit nature of knowledge and the 'silo' effect - constitute classic challenges in the discipline of knowledge management.

The economics, exigencies and culture of social care services can also act as barriers to capturing and sharing knowledge (Bloice and Burnett 2016). Service contracts with local government provide minimal resource for staff to take time away from day-to-day support and undertake extra learning or research. With a high staff turnover in the sector, service managers can also be reluctant to release established staff from practice duties. Hard-pressed support workers are not always likely to embrace the extra work of documenting and analysing their practice. Nonethe- 
less, service managers at Scottish Autism have often reported practitioners undertaking innovative and creative practice but not recognising the value of what they were doing, or having forums in which to share their insights. In response, Scottish Autism has committed to a knowledge management strategy to better recognise, capture and share effective practice across services (Bloice and Burnett 2016; Guldberg et al. 2013).

Anthropological research is often concerned with knowledge practices that are situated and habitual (e.g. Fardon 1995; Harris 2007; Marchand 2010). Discerning the forms that practitioner knowledge takes, accounting for the discourses that circulate in services, and identifying common themes that emerge across locations thus requires a kind of anthropological thinking. Indeed, the discipline of knowledge management has been profoundly influenced by the anthropological work of Jean Lave and Etienne Wenger (1991), who identified 'situated learning' and peer-to-peer interactions as being crucial to apprenticeship in craft practices. Wenger's work on 'communities of practice' as contexts for knowledgesharing has been taken up in a variety of technological and business contexts (Wenger et al. 2002). The approach has informed knowledge-management initiatives at Scottish Autism including practice development teams, online knowledge-sharing forums, an annual staff conference, and knowledge-share events with the wider community. The research programme, begun in 2013, offers practitioners opportunities to come together, reflect, and share knowledge in a systematic, evidence-informed way. If situated learning is crucial to the accumulation of practical knowledge, then situated research can be a means to systematically make that knowledge visible and reflect critically upon practice.

\section{Practitioner Research as Knowledge Management}

Practitioner research - in which professionals gather evidence in order to reflect upon their own work - is well established in professional social work (Keeping 2007; Mitchell et al. 2010) but less frequently used in social care (Shaw et al. 2014). Scottish Autism's appointment of a resident researcher to facilitate such a programme represents an innovative step. The programme at Scottish Autism can also be understood as a form of 'action research', widely used in education contexts, wherein practitioners also seek to answer questions arising from their practice through system- atic enquiry and make and document adjustments as they proceed (Altrichter et al. 1993).

As a form of knowledge management, practitioner research at Scottish Autism has been an important way of addressing some of the issues described above. Providing support practitioners with an opportunity to spend time away from day-to-day practice and join a research team creates a context for reflection. Bringing staff together from diverse, geographically distributed services constitutes a community of practice from across the organisation, providing a forum in which to compare experiences and support strategies. Asking questions of habitual practice makes the knowledge and skills taken for granted by practitioners visible, as well as exposing where knowledge is insufficient or requires development. The research provides a means to document and analyse changes to practice that result from these discussions. In this way, evidence for innovative practice can be captured and shared, supporting the organisation's aspirations for knowledge management.

Action research and evidence-based evaluation often invoke a scientific rationale: practice innovations are posed as hypotheses to be tested, with practice refined according to the result (Altrichter et al. 1993; Pawson and Tilley 1997). In action research, this process is systematised, evidenced and applied. In Schön's (1983) model of reflective practice, this testing and refinement is continuous and iterative. Where hypothesis-testing can help to address specific issues or questions - and some work at Scottish Autism has taken this form - there is also room for research that pursues the more open-ended enquiry that characterises anthropology (Gatt and Ingold 2013; Strathern 2006). In such projects, researchers respond to the concerns and priorities of participants and, if necessary, re-orient their focus as they proceed.

\section{Practitioner Research in Action}

Upon joining Scottish Autism as a researcher-in-residence, I first spent several months in services getting to know practitioners and supported autistic people. This initial period allowed me to build relationships within the organisation and to identify issues and themes that the service community felt would benefit from research. I then developed a series of training workshops for an initial cohort of 14 practitioner researchers who constituted two project teams. In the workshops, we considered research methods, different forms of evidence, the ethics of practice research, 
and the outputs and outcomes that we wanted our research to achieve. The initial workshops were crucial to developing a functioning community of practice. Workshops became a safe space for challenging and honest discussion about practice as well as for addressing any difficulties the team faced as the programme unfolded.

My role as facilitator was important in navigating some of the challenges to reflective practice outlined above. Visiting services to work alongside practitioner researchers supported the regular documentation of practice for case studies. My visits also helped ensure that time set aside for recording and reflection was honoured by managers, who might be juggling competing priorities. Regular workshops with the project teams allowed us to refine our focus and identify emergent themes as we proceeded with the projects. When we began to share our insights in staff workshops and practice resources, the work helped to promote a culture of reflection and analysis across the organisation.

The first practitioner research project focused on voice and participation in autism services, sometimes called 'user participation' or 'user involvement' (Long et al. 2017). Practitioners drawn from a range of services examined ways in which autistic people with varying communication styles and needs could be better empowered to have a say in the way their support was provided. For example, one case study documented the use of mobile technology to allow people who did not communicate verbally to take photos and record video to present their preferred activities in service review meetings. Another example focused on enabling a young man to create a visual timetable, featuring his own selection of activities, in order to establish and advocate his choices to staff and family. Studies of collective participation included evaluating inclusive service forums, a creative performing arts project, and the assembly process in the organisation's residential school.

These adaptations to practice usually relied on the tacit knowledge of practitioners and those they supported. Practitioners constantly adjusted their communication styles using mediums that they knew to be meaningful to those they supported, or responded intuitively to individual's indicators of wellbeing or stress in day-to-day activities. Through documenting this work and creating a space for comparison many of these processes were made explicit and provided clearer grounds for reflection and adjustment of practice.

As situated participant observers, the practitioner researchers involved in the project were alive to wider contextual issues than simply focussing on the cognition of supported autistic people, or pre-designated outcomes from the work being recorded. As case studies unfolded, team members observed differences in staff knowledge and values; or discrepancies in aspiration between supported people, their families and support team. Case studies focussing on technological communication aids highlighted practical limits to mobile technology. This went beyond the functioning of an app, or the thinking style of the individual using it, to take in such issues as wireless coverage in services, staff confidence in using IT, or the need for some individuals to have concrete, printed outputs from choice-making activities in order to process and maintain the decisions that they had made.

The diversity of the case studies reflected the heterogeneous nature of social care for autistic people. Rather than set limited variables to evaluate, practitioner researchers sought to establish common themes from these case studies to inform principles for practice. The staff workshops and practitioner resources that we convened to disseminate research findings emphasised the need for authenticity of voice over third person authorship in service documents; the use of media that were meaningful to the individual, rather than a reliance on written documentation; ownership of the process of producing supports; concrete outputs from choice-making activities to refer to and support self-advocacy; and a shared understanding of choices made between individuals, their families, and support staff (Long et al. 2017, 12-13). Establishing guiding principles in this way proved more relevant to informing personalised services than prescribing specific tools or resources. This approach thus draws more from the reflective and thematic observations of qualitative research than it does on a scientific evaluation.

The second project focused on friendships and sociality in Scottish Autism's services. The topic arose after supported people in a number of services asked their support staff for help in learning how to make friends. The resulting practitioner research project considered how services recognise and facilitate friendships and social opportunities (Long et al. 2018). The project exemplifies the way in which the open-ended and exploratory nature of anthropological research can promote critical discussion and generate unexpected insights.

The team undertook a series of qualitative interviews and focus groups with both staff and supported people on friendship in services. This was accompanied by participant observation within a regular talking group for autistic adults and in two evening 
social groups. The approach provided researchers with an opportunity for thorough engagement with participants. Again, it proved helpful to ask questions about activities as they were being undertaken rather than in interviews later, as this better suited the thinking styles of some of the autistic participants.

The research initially sought to identify good practices for supporting friendships amongst autistic people, and the work in social groups did indeed lead to some helpful principles for facilitating social opportunities. Yet the critical approach taken by the research team, as a reflective community of practice, led to more fundamental discussions around friendship and sociality. A review of research literature on autism and friendship found autistic friendship quality to be largely evaluated against non-autistic norms for social interaction, while practitioners and autistic individuals engaged in our research described meaningful interactions and social attachments that differed from these norms. Drawing on anthropology's mission to recognise diverse forms of sociality, the team considered Elinor Ochs and Olga Solomon's (2010) notion of 'autistic sociality' in order to recognise social attachments that differ from normative models.

A second important finding led us to broader discussions. Both the staff focus groups and talking groups with supported people found that questions around friendship and affective attachment did not just pertain to relations between supported people but often centred on relations between practitioners and those they supported. These insights led us to consider social care as a form of relational support in which interactions and relations with practitioners are central to the lived experience of supported autistic people. The programme's next wave of research is seeking to better understand the dynamics of those relations and services. As such, the reflective conversations of our research team moved from a focus on autistic sociality to a focus on 'diverse sociality': the shift recognised that sociality within services includes relations between autistic people, between autistic people and non-autistic people, between supported people and practitioners (who are themselves a neurodiverse population, including autistic and non-autistic staff) and multiple others. Recognising diverse sociality, rather than comparing autistic friendships to non-autistic norms, allowed us to consider the many interactions and relations that constitute the day-to-day dynamics of autism services (Long et al. 2018). The systematic and holistic documentation of practice contexts from within recognisable to anthropologists as ethnography - offers possibilities to better understand these dynamics. The kinds of critical and reflective debates described here are possible when research projects are open-ended and iterative, and afford space for practitioners to ask fundamental questions of the services in which they work.

\section{Reflective Practitioners and Participant Observers}

Social anthropologists have analysed knowledge management in academic institutions, describing or undertaking critiques of managerial definitions of utility (Jiménez 2008; Strathern 2006). Yet anthropological notions of knowledge can be more evident in some knowledge management practices than institutional discourses might suggest.

In her account of knowledge management in the academy, Marilyn Strathern (2006) critiques the separation of curiosity-led enquiry from processes of 'management' that seek to transmit knowledge across disciplinary boundaries, or into practice contexts. These models would today be recognised in the UK 'impact' agenda within higher education but are equally pertinent in tropes of 'translation', 'knowledge transfer' or Schön's 'techno-rationality'. Such paradigms assume that knowledge producers and knowledge users are different people in different places. Reflecting on Schön's work, Strathern questions whether knowledge generation and knowledge use should be considered as separate processes within the academy. Following the example of 'reflection in action', she suggests that research and knowledge application could be seen as 'enfolded' into the same processes. In my view, the argument that knowledge generated through systematic research can be applied by the same actors that produced it also holds for situated research outside of the academy.

In this respect, the reflective practitioner of Schön and the participant observer of anthropology look very much alike. Participant observation might best be understood as reflexive immersion in a social context in order to gain insights into the lives of people that researchers wish to better understand. The reflective practitioner is someone already immersed in a professional context, but who undertakes a comparable process of enquiry, reflection and critical analysis of practice. Practitioner research offers a means to systematise and collaborate on that process of reflection and refinement.

In research training at Scottish Autism, I have made this analogy between participant observation 
and reflective practice explicit. In workshops, I recount to practitioners that in the classic model of anthropology the researcher historically entered a new social context and had to learn the language, the rules and the social expectations to gain new insights. I suggest that practitioner researchers know how to communicate and know the social rules of the service contexts they are analysing, but need a space to step back and reflect upon what they know. Research workshops provide a space removed from the day-to-day exigencies of practice in order for practitioner researchers to reflect and take a critical perspective. It is in this break, and through comparison of experience, that tacitly held knowledge is made visible, social interaction better understood, and new terminology found for describing service contexts.

\section{Situated Research and Meaningful Inclusion}

Knowing how to communicate in a service context is a highly significant element of research into social care. 'Learning the language' in autism services often means gaining familiarity with individuals' unique communication styles. Communicative competence in autism services will likely include the use of visual supports, understanding unique vocabulary or prosody, and allowing supported people processing time when interacting. In this respect, standardised questionnaires or interviews are rarely appropriate for including autistic people with additional intellectual disabilities in research processes. Many supported individuals also have difficulty dealing with abstract reflection in an interview context rather than discussing concrete issues in a given moment (see Klotz 2004). The engagement of practitioner researchers who are already skilled at communicating with supported autistic individuals therefore opens up considerable possibilities for widening participation in research. As participant observers, practitioner researchers can be alive to the diverse and multiple ways in which subtle social attachments and interactions manifest in supported autistic people. This is particularly pertinent amongst those people who may not use reciprocal verbal interaction as their main means of communicating with others.

The relational nature of anthropological research in which social relations are both the object of study and the means through which researchers gain insight - is relevant here. Autistic people with unique communication and thinking styles are likely to need considerable time to build relations with others and create possibilities for interaction. Practitioner researchers who have built these relations over a period of time may be better placed to gain the perspectives and insights of supported people than unfamiliar academic researchers. This approach may seem uncontroversial to anthropologists, who are used to building and nurturing relations as a means of understanding the perspectives of others, but this intersubjective process can still attract scepticism in the wider field of autism research, which often prizes scientific ideals of objectivity.

The relational element to research requires thorough ethical consideration and the acknowledgement of the power relations between supported people and professionals, however. Careful account needs to be taken as to whether a supported autistic person feels able to be critical of practice with someone who may be one of their support team. Researchers need to be clear, in a way that is meaningful for individual participants, about what they are documenting and when. At Scottish Autism, processes of gaining informed consent included producing narrative visual representations of research processes known as 'social stories' (Gray 2000) and using 'talking mats,' wherein individuals moved symbols and photographs around a dedicated workspace to indicate choices, preferences and consent to take part (Murphy and Cameron 2008). The practitioner research team also discussed at length how they would balance the roles of practitioner and researcher. In particular, the team felt they needed clarity on what to do if any practices of concern or if any safety issues were uncovered in the course of research ( $\mathrm{Av}$ ery 2019). This was particularly important given the necessity for participants to feel able to speak openly to practitioner researchers. Ultimately, the team acknowledged a primary duty of care as practitioners. We decided to make clear to participants from the outset that any issues of serious concern might need to be addressed, but that in that instance the participant would be informed and consulted first. Statutory and professional research guidelines are clear on all of these issues. Working as a professional researcher alongside practitioner researchers provided a means to consider and address these points collectively as well as to ensure that legal and professional obligations were met. It is worth noting that the team also felt an ethical obligation to proceed: for if these concerns are navigated and carefully mitigated, research processes can include members of the autistic population that are often excluded (Avery 2019; Klotz 2004; Russell et al. 2019). 
In reflecting upon practitioner research in social care, some researchers have cautioned that the resulting narratives are not always inclusive enough of supported people's voices (Keeping 2007). Scottish Autism's practitioner researchers took this concern seriously. The decision to focus our first research project on the participation of supported autistic people in support provision meant that the same imperative applied to our research (Long and Clarkson 2017). Team members felt a strong impetus to make case studies as participatory as possible, enabling supported autistic people to engage in a way that was meaningful. For example, one young man enjoyed video sessions more than verbal interviews, because he could take control and demonstrate to the camera activities that he liked doing and explain why. This real-time commentary made more sense to him than reflecting or writing after the event. Supported people's input has been crucial to producing outputs from the work. One of the autistic convenors of a local service forum, documented in our research, has reflected on the process in knowledge-share events. In producing a case study on autistic voice in drama projects, autistic performers co-authored a research poster and spoke on their experiences at a major autism conference. Learning from the initial project, it is an aspiration to move Scottish Autism's programme from 'practitioner research' to 'practice research' in which collaborative ethnography is co-produced by supported autistic people. Development of inclusive support practice and inclusive research practice are thus proceeding in dialogue with one another.

In this form of research, practitioner researchers have a key role in enabling, listening to and acting upon supported autistic people's voices, whatever form those voices may take. Research can then include important exchanges of perspectives between stakeholders as envisaged by Damian Milton (2014). The concerns and experiences of supported autistic people must be central to any such research, however, and researchers must be alive to the risk of practitioner perspectives occluding those of supported people (Woods and Waltz 2019). Milton and others have argued powerfully for wider acknowledgement of autistic knowledge and expertise among professionals (Milton 2014; Milton and Bracher 2013) and for more inclusive and autistic-led research (Chown et al. 2017; Woods and Waltz 2019). Such research includes autistic auto-ethnography (or 'aut-ethnography') as a unique source of insight (Milton 2015). Whilst we acknowledge that the experiences of supported people have thus far been represented with the mediation of practitioners, the anthropologically informed approach described here shares a commitment to attend to the lived experience of supported autistic people. This requires reflexivity of the kind that has emerged in social anthropology in response to post-colonial and feminist critiques: practitioner researchers must acknowledge their place in a social context, including the potential power dynamics and authoritative discourses circulating therein, rather than pretend to detached objectivity.

A recent UK-wide project in which I was involved sought to promote greater autistic participation in research. The project seminars laid down an important challenge to autism researchers to involve autistic people at all stages of the research process - from determining research priorities and designing projects, to guiding meaningful inclusion in data collection and dissemination of results (Fletcher-Watson et al. 2019). This work represents a significant step forward for autistic participation, but there remains an implicit understanding that research is primarily carried out by university-based researchers while its application lies in service contexts. A broader consideration of how and where research might be carried out stands to widen the scope and applicability of autism research. Practice-based research that includes autistic individuals with intellectual disabilities and diverse communication styles is well placed to respond to the priorities of supported people. As such, this type of research can usefully evolve in dialogue with university-based research that is also inclusive and attentive to autistic people's priorities and experiences.

\section{Conclusion}

Practitioner research at Scottish Autism has fed into critical discussion and practice development across the organisation's services. The research has been presented at practitioner workshops and has prompted critical reflection and discussion at the organisation's staff conference. The team has produced evidence-informed training materials for Scottish Autism's learning and development programme, and has shared its findings with wider practice communities through knowledge-share events and practice journals. The research programme recounted here illustrates that situated practice research can be key to nurturing critical conversations about practice and informing support for autistic people. This model systematises the process of 'reflection in action' as envisaged by Schön, and provides a departure from the 'techno-rationality' or 'translation' paradigm that dominates autism research. 
This argument is not intended to dismiss the importance of wider autism research. Team members accessed research on autistic thinking and communication to inform processes of inclusion, and we referred to critical autism studies to support our discussions around diverse sociality. Rather, our process brought scientific evidence and practice-based evidence into dialogue with one another instead of effecting a one-way flow of translation and application. If such dialogue is practised at a broader level, situated practice research has the potential to achieve more than feeding back into practice within a single organisation in the manner of action research, or contributing to internal knowledge management. By responding to concerns of supported people and practitioners within services, engaging the voices and lived experience of supported autistic people, and providing a holistic account of service dynamics, such research can make a valuable contribution to the wider field. Research grounded in day-to-day practice offers perspectives and findings that can guide future priorities and help scientists to take greater cognisance of service dynamics.

The approach to research outlined here can provide unique insights that are applicable and relevant to improving social care for autistic people. In this model, professional anthropologists can have a role as facilitators of participant observation and systematic reflection. Situated practice research of this kind has much to offer a pluralistic field of autism research which, as the autistic community has long stated, should be re-balanced to reflect the experiences and priorities of autistic people, including those with intellectual disabilities. This requires thinking beyond the trope of 'translation' to consider critically how autism knowledge is generated and shared.

\section{Acknowledgements}

I would like to thank the many supported autistic people and autism practitioners within Scottish Autism who have generously shared their insights and experience as collaborators and participants in the research described here. I also wish to acknowledge Scottish Autism's Deputy CEO, Charlene Tait, whose vision and support to initiate a practice research programme has given us the opportunity to explore new ways of working.

JosePH J. Long is Research Manager at Scottish Autism, where he leads a programme of applied re- search in social care and education services. He is an Associate of the Edinburgh Centre for Medical Anthropology. E-mail: joseph.long@scottishautism.org

\section{Notes}

1. See Klotz (2004) for an overview and critique of early ethnographic studies of intellectual disability.

2. Also referred to as 'learning disability' in policy and practice literature.

3. The third sector in the United Kingdom comprises organisations which are neither state agencies nor private businesses, but charities and non-profit organisations that provide services commissioned by the state.

4. All of this work falls into the category of translational research, according to institutions such as the US Institute of Medicine, which class translation of 'basic' research into practice as ' $\mathrm{T} 1$ ' and scientific trials as 'T2' research (Woolf 2008).

5. The idea of tacit knowledge has been explored comprehensively in the work of Harry Collins. See Collins (2010) for an overview.

\section{References}

Aitken, K. (2013), 'The Autism Spectrum: The Changing Context of Diagnosis, Research and Practice', Good Autism Practice (GAP) 14, no. 2: 78-86, https://www.ingentaconnect.com/content/bild/ gap/2013/00000014/A00102s1/art00012?crawler=true.

Altrichter, H., P. Posch and B. Somekh (1993), Teachers Investigate Their Work (London, Routledge).

Angrosino, M. V. (1998), Opportunity House: Ethnographic Stories of Mental Retardation. Vol. 2 (Walnut Creek, CA: AltaMira Press).

American Psychiatric Association (2013), Diagnostic and Statistical Manual of Mental Disorders (DSM-5®) (Arlington, VA: American Psychiatric Publications).

Avery, J. D. (2019), 'Ethical Dilemmas and Moral Conundrums: Negotiating the Unforeseen Challenges of Ethnographic Fieldwork', Anthropology in Action 26, no. 3: 1-9, doi:10.3167/aia.2019.260301.

Avery, J. D. (2020), An Ethnography of Severe Intellectual Disability: Becoming 'Dirty Little Freaks' (London: Palgrave).

Belek, B. (2019), 'Autism', Cambridge Encyclopedia of Anthropology, https://www.anthroencyclopedia.com/ entry/autism (accessed 18 December 2019).

Bloice, L. and S. Burnett (2016), 'Barriers to Knowledge Sharing in Third Sector Social Care: A Case Study', 
Journal of Knowledge Management 20, no. 1: 125-145, doi:10.1108/JKM-12-2014-0495.

Brugha, T. S., S. McManus, J. Bankart, F. Scott, S. Purdon, J. Smith ... and H. Meltzer (2011), 'Epidemiology of Autism Spectrum Disorders in Adults in the Community in England', Archives of General Psychiatry 68, no. 5: 459-465, doi:10.1001/ archgenpsychiatry.2011.38.

Chown, N., J. Robinson, L. Beardon, J. Downing, L. Hughes, J. Leatherland ... and D. MacGregor (2017), 'Improving Research about Us, with Us: A Draft Framework for Inclusive Autism Research', Disability \& Society 32, no. 5: 720-734, doi:10.1080/ 09687599.2017.1320273.

Collins, H. (2010), Tacit and Explicit Knowledge (Chicago: University of Chicago Press).

Fardon, R. (1995), Counterworks: Managing the Diversity of Knowledge (London: Routledge).

Fletcher-Watson, S., J. Adams, K. Brook, T. Charman, L. Crane, J. Cusack . . E. E. Pellicano (2019), 'Making the Future Together: Shaping Autism Research through Meaningful Participation', Autism 23, no. 4: 943-953, doi:10.1177/1362361318786721.

Gatt, C. and T. Ingold (2013), 'From Description to Correspondence: Anthropology in Real Time', in Design Anthropology: Juxtaposing Theory and Practice, (eds) W. Gunn, T. Otto and R. Smith (London: Bloomsbury), 139-158.

Gleason, J. J. (1989), Special Education in Context: An Ethnographic Study of Persons with Developmental Disabilities (Cambridge: Cambridge University Press).

Gray, C. (2000), The New Social Story Book (Arlington, VA: Future Horizons).

Grinker, R. R. (2008), Unstrange Minds: A Father Remaps the World of Autism (London: Icon).

Guldberg, K. R., J. Mackness, E. Makriyannis and C. Tait (2013), 'Knowledge Management and Value Creation in a Third Sector Organisation', Knowledge and Process Management 20, no. 3: 113-122. doi:10.1002/kpm.1410.

Harris, Mark. (2007), Ways of Knowing: New Approaches in the Anthropology of Knowledge and Learning (Oxford: Berghahn).

Hollin, G. (2014), ‘Constructing a Social Subject: Autism and Human Sociality in the 1980s', History of the Human Sciences 27, no. 4: 98-115, doi:10.1177/0952695114528189.

Jiménez, A. C. (2008), 'Relations and Disproportions: The Labor of Scholarship in the Knowledge Economy', American Ethnologist 35, no. 2: 229-242, doi:10.1111/j.1548-1425.2008.00035.x.

Keeping, C. (2007), 'Practitioner Research', in The Critical Practitioner in Social Work and Health Care, (eds) S. Fraser and S Matthews (London: Sage), 132-148.
Klotz, J. (2004), 'Sociocultural Study of Intellectual Disability: Moving beyond Labelling and Social Constructionist Perspectives', British Journal of Learning Disabilities 32, no. 2: 93-104, doi:10.1111/ j.1468-3156.2004.00285.x.

Lave, J. and E. Wenger (1991), Situated Learning: Legitimate Peripheral Participation (Cambridge: Cambridge University Press).

Long, J., J. Brown, S. Daly, K. Gibson, and C. McNeillis. (2018), 'Friendship and Sociality in Autism Services'. Good Autism Practice 19 (1): 22-31.

Long, J. and A. Clarkson (2017), 'Towards Meaningful Participation in Research and Support Practice: Effecting Change in Autism Services', in Autism and Intellectual Disability in Adults Vol. 2, (ed.) D. Milton and N. Martin (Brighton, UK: Pavilion), pp. 41-45.

Long, J., J. Panese, J. Ferguson, M. A. Hamill and J. Miller (2017), 'Enabling Voice and Participation in Autism Services: Using Practitioner Research to Develop Inclusive Practice', Good Autism Practice 18, no. 2: 6-14, https://www.ingentaconnect.com/cont ent/bild/gap/2017/00000018/00000002;jsessionid=2eo vvil864bal.x-ic-live-03.

MacKay, T., M. Knapp, J. M. Boyle, V. Lemmi, M. Connolly and A. Rehill (2018), The Microsegmentation of the Autism Spectrum: Economic and Research Implications for Scotland (Edinburgh: Government of Scotland).

Malcolm, R., S. Ecks and M. Pickersgill (2018), '“It Just Opens up Their World": Autism, Empathy, and the Therapeutic Effects of Equine Interactions', Anthropology \& Medicine 25, no. 2: 220-234, doi:10.1080/136 48470.2017.1291115.

Mandell, D. S., A. C. Stahmer, S. Shin, M. Xie, E. Reisinger and S. C. Marcus (2013), 'The Role of Treatment Fidelity on Outcomes during a Randomized Field Trial of an Autism Intervention', Autism 17, no. 3: 281-295, doi:10.1177/1362361312473666.

Marchand, T. (2010), ‘Making Knowledge: Explorations of the Indissoluble Relation between Minds, Bodies, and Environment'. Journal of the Royal Anthropological Institute 16: S1-21.

Milton, D. E. M. (2012), 'On the Ontological Status of Autism: The "Double Empathy Problem"', Disability $\mathcal{E}$ Society 27, no. 6: 883-887, doi:10.1080/09687599.20 12.710008 .

Milton, D. E. M. (2014), 'Autistic Expertise: A Critical Reflection on the Production of Knowledge in Autism Studies', Autism 18, no. 7: 794-802, doi:10.1177/1362361314525281.

Milton, D. E. M. (2015), 'Aut-Ethnography: Working from the Inside Out', The Autism Anthropologist Blog, 19 January, https://theautismanthropologist.word 
press.com/2015/01/19/aut-ethnography-workingfrom-the-inside-out/.

Milton, D. E. M. and M. Bracher (2013), 'Autistics Speak but Are They Heard?' Medical Sociology Online 7, no. 2: 61-69, http://www.medicalsociologyonline .org/resources/Vol7Iss2/MSo_7.2_Autistics-speakbut-are-they-heard_Milton-and-Bracher.pdf.

Mitchell, F., N. Lunt, and I. Shaw (2010), 'Practitioner Research in Social Work: A Knowledge Review', Evidence \& Policy: A Journal of Research, Debate and Practice 6 (1): 7-31, https://doi.org/10.1332/1744264 $10 X 482971$.

Murphy, J. and L. Cameron (2008), ‘The Effectiveness of Talking Mats with People with Intellectual Disability', British Journal of Learning Disabilities 36, no. 4: 232-241, doi:10.1111/j.1468-3156.2008.00490.x.

Ochs, E. and O. Solomon (2010), 'Autistic Sociality', Ethos 38, no. 1: 69-92, doi:10.1111/j.1548-1352.2009 .01082.x.

Pawson, R. and N. Tilley (1997), Realistic Evaluation (London: Sage).

Pellicano, E., A. Dinsmore and T. Charman (2013), A Future Made Together: Shaping Autism Research in the UK (London: Institute of Education, University of London), http://discovery.ucl.ac.uk/10017703/.

Pellicano, E., A. Dinsmore and T. Charman (2014), 'What Should Autism Research Focus Upon? Community Views and Priorities from the United Kingdom', Autism 18, no. 7: 756-770, doi:10.1177/1362361314529627.

Russell, G., W. Mandy, D. Elliott, R. White, T. Pittwood and T. Ford (2019), 'Selection Bias on Intellectual Ability in Autism Research: A Cross-Sectional Review and Meta-Analysis', Molecular Autism 10, no. 9, doi:10.1186/s13229-019-0260-x.

Schön, D. A. (1983), The Reflective Practitioner: How Professionals Think in Action (New York: Basic Books).

Shaw, Ian F., Neil Lunt, and Fiona Mitchell (2014), 'Practitioner Research in Social Care: A Review and Recommendations' (London: NIHR School for Social Care Research).
Sinclair, J. (2012), 'Don't Mourn for Us', Autonomy: The Critical Journal of Interdisciplinary Autism Studies 1, no. 1, http://www.larry-arnold.net/Autonomy/index .php/autonomy/article/view/AR1.

Sinclair, J. (2013), 'Why I Dislike "Person First" Language', Autonomy: The Critical Journal of Interdisciplinary Autism Studies 1, no. 2, http://www.larryarnold.net/Autonomy/index.php/autonomy/article/ view/OP1.

Singer, J. (2017), Neurodiversity: The Birth of an Idea (SelfPublished: Amazon).

Solomon, O. (2010a), 'Sense and the Senses: Anthropology and the Study of Autism', Annual Review of Anthropology 39: 241-259, doi:10.1146/annurev .anthro.012809.105012.

Solomon, O. (2010b), ‘What a Dog Can Do: Children with Autism and Therapy Dogs in Social Interaction', Ethos 38, no. 1: 143-166, doi:10.1111/j.1548-1352.2010.01085.x.

Strathern, M. (2006), 'Useful Knowledge', Proceedings of the British Academy 139: 73-109.

Wenger, E., R. A. McDermott and W. Snyder (2002), Cultivating Communities of Practice: A Guide to Managing Knowledge (Cambridge, MA: Harvard Business Press).

Woods, R., D. Milton, L. Arnold and S. Graby (2018), 'Redefining Critical Autism Studies: A More Inclusive Interpretation', Disability \& Society 33, no. 6: 974-979, doi:10.1080/09687599.2018.1454380.

Woods, R. and M. Waltz (2019), 'The Strength of Autistic Expertise and Its Implications for Autism Knowledge Production: A Response to Damian Milton', Autonomy: The Critical Journal of Interdisciplinary Autism Studies 1, no. 6, http://www.larry-arnold.net/ Autonomy/index.php/autonomy/article/view/CO2.

Woolf, S. H. (2008), 'The Meaning of Translational Research and Why It Matters', Journal of American Medical Association 299, no. 2: 211-213, doi:10.1001/ jama.2007.26. 